\title{
Children as Researchers: Wild Things and the Dialogic Imagination
}

\section{Authors:}

Megan Lang, University of Tasmania

Becky Shelley, University of Tasmania

We wish to acknowledge our colleagues, Suzie Wright, who sadly left us too soon, and Assoc. Prof. Noleine Fitzallen, both of whom contributed so much to this project.

Child-led research is no longer a novel concept. Given appropriate guidance, children's capabilities as researchers and co-researchers have been repeatedly demonstrated (Kellett, 2010; Lundy and McEvoy, 2012; O'Donnell, 2017). Children's contributions to knowledge are valuable and substantial, offering fresh perspectives and insights that are often invisible to the eyes of adults (Thomas, 2017). From overlooked research questions such as dangers to children's hearing in public toilets (Keegan, 2019) through child-researchers positioned to conduct research with their peers where adults have limited connection (Save the Children, 2010) to evaluations of extra-curricular education programs (O'Donnell, 2017), children can be enabled to conduct research, thus directly contributing to the discussion of issues that affect them.

In spite of excellent examples of child-led research, questions remain about the implications for childhood studies of children's participation in what are often adult-designed research activities. Adults retain control of most aspects of participation, particularly dissemination (Harden et al., 2000). Even when children are supported in developing and evidencing their views, adults may overlook the importance of audience and impact and neglect to facilitate these essential elements (Lundy, 2007). The idea that participatory research "empowers" children may obscure the effects of tacit expectations that children participate in ways and for purposes designed by adults (Crowley, 2015; Gallacher and Gallagher, 2008; Skelton, 2008). Further, children's participation in research designed by adults and/or in creating knowledge about themselves may encourage them to "take 
part in the processes used to regulate them" (Gallacher and Gallagher, 2008, p. 504). Implicit in all these factors is the question of whose perspective is being heard, of "how do we know who is speaking?" (Baker, 1999, p. 365; cited in Gonzalez, Hernandez-Saca and Artiles, 2017).

This paper problematises the questions of who is speaking, who is being heard, and considers the importance of context. We argue that listening to children requires awareness of the communicative space, specifically the recognition that, in addition to spoken voices, many other voices and silences are present. Further, voices that are silent and/or omitted are as salient as those that are privileged and present. Voices are manifold. They include who is selected and/or chooses (or declines) to participate; goals, motivations and biases of all participants; social, physical and cultural characteristics, including humour; everyday negotiation of social and cultural boundaries; and physical engagements with the environment - all within the temporal context of a situation. Deeper understanding requires that all these voices be brought to awareness. Adopting this perspective entails not just permitting but planning for children's voices to arise in response to context, possibly in irrational and unintentional ways. We posit that such communicative space is essential to children's fully experiencing the behavioural and aspirational roles associated with a situation (in this case being a researcher) and to facilitating adult awareness and self-critical reflection.

In exploring the intertwined and chaotic nature of the social world that is child-led research, this paper will present some key concepts from the dialogic imagination of Mikhail Bakhtin. These concepts serve as a heuristic for examining "Tassie Researchers", a five-day children-as-researchers program. Experiences and observations of the program are unpacked and the different voices of the situation highlighted. This is followed by a discussion of findings and implications. But first, it is important to question the assumptions informing this paper as to how children and childhood are defined and understood. 


\section{Who is speaking? Children and childhood}

Attending to different voices can be challenging. This challenge is exacerbated by simplifications of the multi-layerdness of reality, for example in the view of adults and children in terms of a maturitybased dichotomy. Children have been viewed as potential-filled adults-in-the-making, victims of adult-child power relations, as agentic beings, and capable experts in their own experience (Morrow, 2005; Horgan, 2017; Thomas, 2017). Although any one of these viewpoints may be valid at a given moment, a broader perspective on childhood is one that views children (and all people) as beings at temporal intersections at which influences of social, cultural, and bodily and other material elements combine (Alanen, 2009; Honig, 2009; Spyrou, 2019). Thus, children are not merely defined by maturity or age, but also by gender, ethnicity, culture, class, and situation at a moment in time. In such a holistic view, interactions with adults are performative. Children will present or remain silent about aspects of themselves and their lives according to how they wish to portray themselves, how they are navigating particular issues and power dynamics, and/or what they think the adult already knows or wishes to see (Spyrou, 2016). These elements or 'voices' are unique to an interaction, but make connections to the lived experience, knowledge, and social and cultural understandings of each interlocutor, including the genres of behaviour implicit in their role and personal identities. Observing these voices, and the tension between them, requires a way of examining a situation that exposes its layers as well as the viewer's own position. It calls for an expansion of ontological understanding that embraces children, adults and the material world and looks for, not what childhood is, but "how childhood is done" (Spyrou, 2019, p.318). The dialogic imagination is such a method.

\section{Dialogism as heuristic}

This paper adopts a dialogical heuristic derived from the work of Mikhail Bakhtin (e.g. Bakhtin, 1984). Bakhtin observed that reality consists of many different perspectives - a cacophony of voices that he called a heteroglossia. He noticed that meaning is created in the 'space' between interlocuters, in 
the moment of interaction (Wegerif, 2008). This view stands in opposition to the idea that meaning is telegraphed from one entity to another, as in rhetoric. Bakhtin was sensitive to voices' responsiveness to one another, with authority in balance in the sense that no voice always holds dominance.

Bakhtin's notions of heteroglossia grew from his examinations of literature but are useful for other domains. In the social sciences, dialogism draws on the idea of heteroglossia as a reminder to constantly see the world in inter-relational terms $(\mathrm{Ooi}, 2013)$ and that any answer must lead to a new question, because otherwise dialogue is ended (Wegerif, 2019). Heteroglossia is also a reminder that true communication has the potential to be unsettling and to bring about change, even for the most powerful parties (Murray, 2000). Such transformation becomes possible because one's own perspective is "made visible from the perspectives of others" (Robinson, 2011, p. 7). True communication therefore carries with it a willingness to accept risk, namely "risk of response as unrecoverable exposure to the other" (Nealon, 1997, p. 146).

Closely related to heteroglossia are the concepts of polyphony and the carnivalesque. Bakhtin described polyphony as voices that together exert a harmonising influence or narrative within the cacophony of a heteroglossia, and which are therefore characterised by both harmony and tension. The carnivalesque highlights the existence of chaos, conflicts and negotiation (Ooi, 2013). It reflects Bakhtin's interest in the medieval carnival, which celebrated folk cultures and the (temporary) upending of social hierarchies. Authority was resisted and ridiculed, but always within the framework of that authority, stopping short of destruction:

[In carnival], what is suspended first of all is the hierarchical structure - that is, everything resulting from socio-hierarchical inequality or any other form of inequality among people (including age). All distance between people is suspended, and a special carnival category goes into effect: free and familiar contact among people (Bakhtin, 1963;1984, p. 123).

In terms of social research, the carnivalesque emphasises both the existence of socially or culturally sanctioned and marginalised ideas, interpretations and stories, and the fluidity of their presence and 
status (Ooi, 2013). This kind of emphasis is pertinent to contexts familiar to children, such as classroom situations. For example, Mallan (1999) described how, when given autonomy and unaccustomed access to props, groups of school students created skits confronting to the authority of the teachers and subversive of 'normal' behaviours in the classroom. In effect, the students used storytelling as "a means of disruption and playful anarchy within the authoritative discourse of the classroom" (Mallan, 1999, p. 113). Similarly, Grace \& Tobin (2002) described how, when given free rein in a video-making class, some children created stories transgressing classroom norms of appropriate subjects and humour. In both cases, such transgressions were sources of hilarity among the children and their peers, fostering a sense of community. In contrast, for adults, children's expressions of the carnivalesque can be experienced as destabilising. Grace and Tobin (2002, p. 212) described their school colleagues' refusal to accept that children's carnivalesque behaviour could be interpreted as a valid expression of their worlds, responding that:

Our point is not to celebrate or romanticize the children's transgressions of classroom norms and values or to suggest that we should write them into our curricula, with, for instance, butt jokes scheduled right after morning recess. Rather, it is to validate the humor and everyday interests of children and to suggest that they have a place in the classroom, in the delicate, fragile, and shifting balance between excess and constraint.

Willingness to embrace expressions of the carnivalesque rests on the knowledge that multiple perspectives held in tension will introduce new - and unpredictable - meanings and directions (Wegerif, 2008). For children, perhaps more immediately than for adults, carnivalesque moments may enable living out and developing 'personhood' (White, 2014). As McKenzie has suggested (2005, p. 91):

The carnivalesque challenges children to think about the social order through the reversal of roles, and in the closure brought about by the ending of the carnival, an increased awareness of the social nature of being-in-the-world.

Adult participation in the carnivalesque will often cause such moments to vanish. Instead, there is the potential for adults to adopt a complex 'insider-outsider' role to maintain a situational 
environment in which suspension of seriousness and promotion of carnivalesque behaviour is possible (White, 2014). Adults then become a reference point for transgression and incongruity.

We propose that child-led and participatory action research would benefit from a stance that acknowledges heteroglossia, polyphony and the carnivalesque. This stance supports self-critical reflection and engagement with children's perspectives and the many forms that children's voices take. It recognises childhood as only one part of the socio-cultural and embodied tapestry that is 'being' a child. At the same time, the validity of adult goals and motivations are recognised. The dialogic imagination fosters ontological awareness about the meaning(s) of 'being' in a research process with children and adults, particularly within research that aspires to be 'child-led' or participatory action research within childhood studies.

\section{Tassie Researchers}

Tassie Researchers was devised as one part of a child-led and child-centred research strategy developed by the authors. Tassie Researchers enables children to conduct their own social research and collect data on issues that concern or interest them, with the aims of exploring and refining this child-led research method, teaching critical and statistical thinking skills to children, and facilitating children's voices on issues that concern them. This paper reflects on the pilot of the Tassie Researchers program, conducted at a local school, in which 15 participants aged 7 to 11 years took part.

The adult research team comprised four people: the authors, who initiated the project, and two scholars from the education faculty who are trained and experienced teachers. These 'teacherresearchers' joined the project shortly prior to the pilot and guided the teaching plan. The pilot ran for five days, divided over two weeks, including dissemination and analysis of a survey that was collated and refined by one of the researchers using questions devised by the children. The children 
provided research data through reflections in notebooks and data representations. For more information on the pilot Tassie Researchers, see Wright et al., (2019).

The research centre where the authors work aims to foster educational opportunities, particularly for children who experience marginalisation and disadvantage. That said, the process for selecting child participants for Tassie Researchers reflects some of the barriers such children experience. Firstly, only children with signed and returned consent forms were able to participate. Non-return of forms may represent self-exclusion, perhaps a consequence of disengagement, literacy or language skills, and/or poor communication. Secondly, the children were nominated by teachers according to their perceived ability to benefit from extension activities, a practice which is also likely to exclude children who are often unheard. We therefore acknowledge that, within the cacophony and polyphony of Tassie Researchers, there are voices that are silent and/or omitted.

\section{The heteroglossia}

The authors' first intention in developing the Tassie Researchers program was to facilitate children's voices in ways that respected children as agentic, rights-holding beings, informed by the literature on children's rights and participatory research. However, early on we experienced anxiety regarding a lack of practical experience as teachers and in managing groups of children and the potential for this to undermine the project goals. This realisation prompted the initial invitation to the teacherresearchers to join the team, a decision that shaped the experience of Tassie Researchers for all participants in the project. The conceptualisation of the children in the project as first and foremost student-learners in a school was reflected in the way the project unfolded - teacher-researcher 1 stood at the front of the room and instructed the children who were seated in front of her. Teacherresearcher 2 sat with the children and initiated the ice-breaker, thus establishing the rules of the game and adult expectations. Researcher 1 also sat with the children but took part in the ice-breaker as if she were a child peer. Researcher 2 sat to the side and observed. 
Written researcher reflections created after conclusion of the project revealed differences in priorities among the four researchers. Teacher-researcher 1 was primarily interested in developing children's skills and understanding, including thinking within, beyond and behind the data, and ultimately to come back to data to inform decisions. Teacher-researcher 2 was interested in teaching critical thinking skills and in awakening an understanding in the children that research involves more than doing a Google search. She also wanted to gain insight into the things that children saw as important, to create better teaching experiences and help children be more engaged in their learning. The researchers who initiated the project were interested to see how the program would unfold, how the children would respond, and to learn more about working with children in this way. These post-program reflections highlighted how adult roles shaped the situation and raised questions about what was imparted to the children. The teacher-trained researchers maintained a focus on skills and knowledge, whereas the other two researchers were interested in ideas of justice, agency and equity. Recognising these different stances was an important starting point for examining our conceptualisations of the children in the Tassie Researchers situation.

\section{Polyphony}

As the project proceeded, the non-teacher researchers noted that the emphasis tended to be on learning outcomes, as opposed to facilitating children's voices on issues that concerned them. Although the children did investigate topics that they devised and that were relevant to their lives, these were secondary to the learning goals of the activity, namely asking statistical questions and analysing statistical data. When the researchers asked the children to brainstorm on graffiti boards to generate topics for investigation, the children began by asking questions such as: are heaven and hell real? How did the dinosaurs die? Who made YouTube? Are wild dogs mean? These questions were gently but swiftly silenced in favour of other brainstormed questions, such as: What school subject is most important? Who litters more, grade $1 / 2$ or grade $5 / 6$ ? How much time on digital devices do kids have? At the time, this process seemed logical and unproblematic. Upon reflection, it was clear that more time could have been spent exploring philosophically those non-statistical 
questions that were important to children. It should be noted that, although these questions were not pursued after the first day, children's understandings and motivations persisted and were expressed again on later days. This carnivalesque occurrence is explored further below.

Conducting the project within a school was a major part of the polyphony of Tassie Researchers. In delivering the material, adult authority was established along school lines: the project took place in a classroom at the school and proceedings were controlled by adults. Adults directed how time was spent and when breaks for lunch would occur. At the start of each session, they stood at the front of the room with the children sitting cross-legged on the floor. When a teacher-researcher wished to attract the children's attention and signal them to be quiet, they initiated a clapped rhythm, with the tacit expectation that the children repeat it (a familiar trope in Australian classrooms). The children complied with this dominant 'narrative', responding to the social expectations associated with being school students.

Other elements of the program included t-shirts, stationery sets, and food - all provided by the visiting researchers. For the researchers, these elements were meant to engage children's interest and positivity, with the t-shirts also intended to anonymise school uniforms for photographs. We were invoking a sense of hospitality and engaging in a transaction of gifts for engagement. However, for the children they seemed to carry a different kind of importance. Some children wanted to ensure that they had a t-shirt that fitted (we had ordered over-sized shirts to be sure they fitted over uniforms), or pens and paper of certain colours in their stationery sets. The hesitation with which these children communicated their wishes to us showed that they were aware that such things may not be considered important by the adults in this situation, but when given permission to swap with their peers they did so immediately and energetically. Some students were uncomfortable with openly rejecting the catered lunch, and only expressed their preferences for other foods (such as plain bread rolls instead of sandwiches) when prompted by researchers who noticed they were not eating. These actions are further manifestations of children interacting with a new situation, drawing 
on their knowledge of social expectations based on acceptable school behaviours as well as cultural and social experience. The embodied experience of food and objects is integral to this interaction, as are the ways in which each person participates, whether adult or child.

\section{Carnivalesque}

There were moments of seeming disorder within the project that are examples of the carnivalesque. For example, the children mixed philosophical, social and scientific questions and ranged freely between questions that required a Google search or an opinion and those that invited statistical study. This chaotic situation was ordered via a dominant narrative of teaching and learning research skills. Resulting tensions were expressed through the resurfacing of certain elements as some children returned to initial brainstorming ideas beyond the first day of the project, such as wild things, gemstones, and dinosaurs. One child wrote in their reflection notebook:

I think a researcher is someone who is into research. I can do this by focusing. I have learned about Dinosaurs. I want to learn about: Dinosaurs.

Or another, who wrote that:

I now know that people like puppies because they are cute. I want to learn more about getting a puppy dog. I could do this by asking questions on the whiteboard.

These extracts show how the children drew on their experience and knowledge to participate in this new social situation of 'being a researcher', at the same time foregrounding their own interests. The objective value of "focusing" or "asking questions on the whiteboard" was recognised and connected to the children's desire to learn about dinosaurs or get a puppy. Whether this 'upending' of the research narrative was deliberate or not is irrelevant. Important is that it constitutes a 'voice' within the situation that offers information about what strands of experience the children are drawing on. Awareness of this 'voice' enriches an adult viewpoint beyond noting that the children require further instruction and/or practice to reach full understanding of the activity. 
There were minor transgressions of expected school behaviour during the project, such as

occasionally omitting to raise a hand when offering a point of view, or giving the researchers hugs and/or secretly passing notes with friendly messages, such as "you're the best". Apart from notepassing being frowned upon in classrooms, the act of initiating a friendship with an adult outside family could be regarded as transgressive. In this view, the children were exploring boundaries of appropriate behaviour for the situation and learning about unfamiliar social expectations.

When asked to reflect on what they had learned, some children spontaneously drew pictures. Some of these can be seen as carnivalesque responses to the 'order' of the situation, such as a dog standing on poo, depicting results as 'winners and losers', or drawing pictures of tigers and dinosaurs during a written task. These elements were entirely initiated by the children and were drawn in their reflection notebooks.
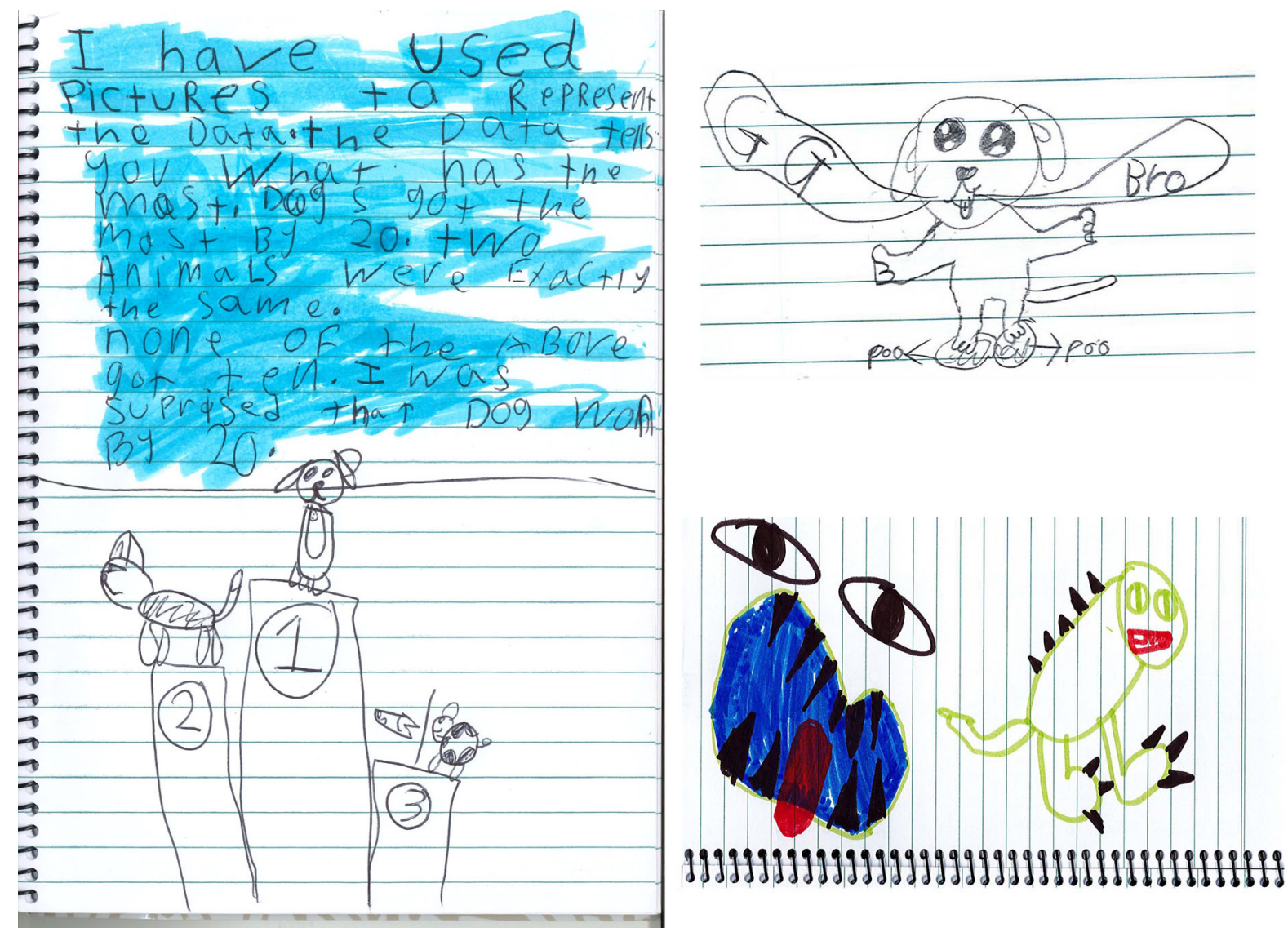

Figure 1 
Another moment of carnivalesque conduct occurred during discussion about dissemination of findings. The discussion began seriously, with suggestions related to the school, such as "present findings at assembly" or "make posters to hang in the school office". Then the children suggested showing their findings to "other researchers" and some of them began joking, suggesting "the world!", "the news!" and "the Queen!". As the possible scope of dissemination expanded and was taken seriously by the researchers (including inviting the Governor of Tasmania to visit as representative of the Queen), the very real possibilities of communication with the world became apparent. The children were impressed, one of them saying: "this blows my mind".

\section{Constructing meaning - children and adults}

\section{A new genre: being a researcher}

The children were excited about being Tassie Researchers. Many of them wore their t-shirts with pride and some wore the name badges they had made for months afterwards. When asked to reflect on what a researcher is, responses referred to scientists, people who collect data and ask questions in order to "know things", and thinkers who tell people what to do. The children all recognised that they had learned researcher skills such as gathering data, making a survey, and making graphs. When asked about what they might do next, a few showed a sense that they could continue being researchers, as one child wrote in their notebook:

I have learned about how to reflect on our question. I now know [how to] do some graphing ... I can do [this] and think of more questions to research on.

Another showed how their understanding of research and being a researcher extended to what other people know, and that the perspectives of others are important:

Researchers do research because they want to get a person side of view to learn about them. I now know how to do a survey and collect data. I want to learn how to collect data that people don't know about. I can do this by talking to experts. 
Most children positioned themselves as learners rather than researchers, writing that they wanted "to learn more about being a researcher". However, all the children felt confident to describe what a researcher is, as in the child who wrote that:

I now know researchers are clever, smart thinkers and they use graphs for important stuff.

When asked about the conclusions they could draw from their data, and what surprised them, the children drew on their understandings and motivations to inform "being a researcher". For example, one child had contributed some survey questions about the kinds of activities other children at their school did at home. In response to the overwhelming number of children who responded that they spent time on devices, this child wrote that:

The data can tell me that I should play sports first before the device. Because sports will keep me healthy and active.

These conclusions were not in the data, but added as a possible explanation or implication. This was a common phenomenon, with children making assumptions that were not in the data, but which may have made sense based on their experience, such as:

More people use electronic devices on weekend because they have no school and it is free time.

These connections from outside the data may have arisen in the hope that they would deliver what the adult researchers were looking for. Teacher-researcher 1 emphasised to the children that conclusions should be sought in the empirical data, and that the children should not make guesses but describe what they see. The children clearly found it challenging to judge where, how and if they should draw on their prior understanding. Some children responded by describing their graphs more literally, one writing how the graph "goes lower numbers to higher numbers", and another that "the graph has lots of up turns and down twists". 


\section{Making data representations}

The children worked in groups to make visual representations of their data, supported by the researchers. In terms of the dialogic imagination, this activity consisted of tension between voices: each of the researchers carried knowledge about how to represent data and a desire to help and/or facilitate the children in their task, but also a belief that they should limit their influence on creating the data representations so that the children could explore the meaning in the data themselves.

Three examples serve to illustrate how generating meaning about the data and the representations were shaped by both the adults and children in the interaction. Figure 2 shows a representation created by a seven-year-old participant. His graph was made in response to a suggestion by one of the teacher-researchers to represent the number of each item in columns. The child used this idea to accommodate numerous examples of carnivalesque humour, including a pig with an overlong tail, playful monkeys, a flying lizard, and hamsters with pointy teeth and glasses.

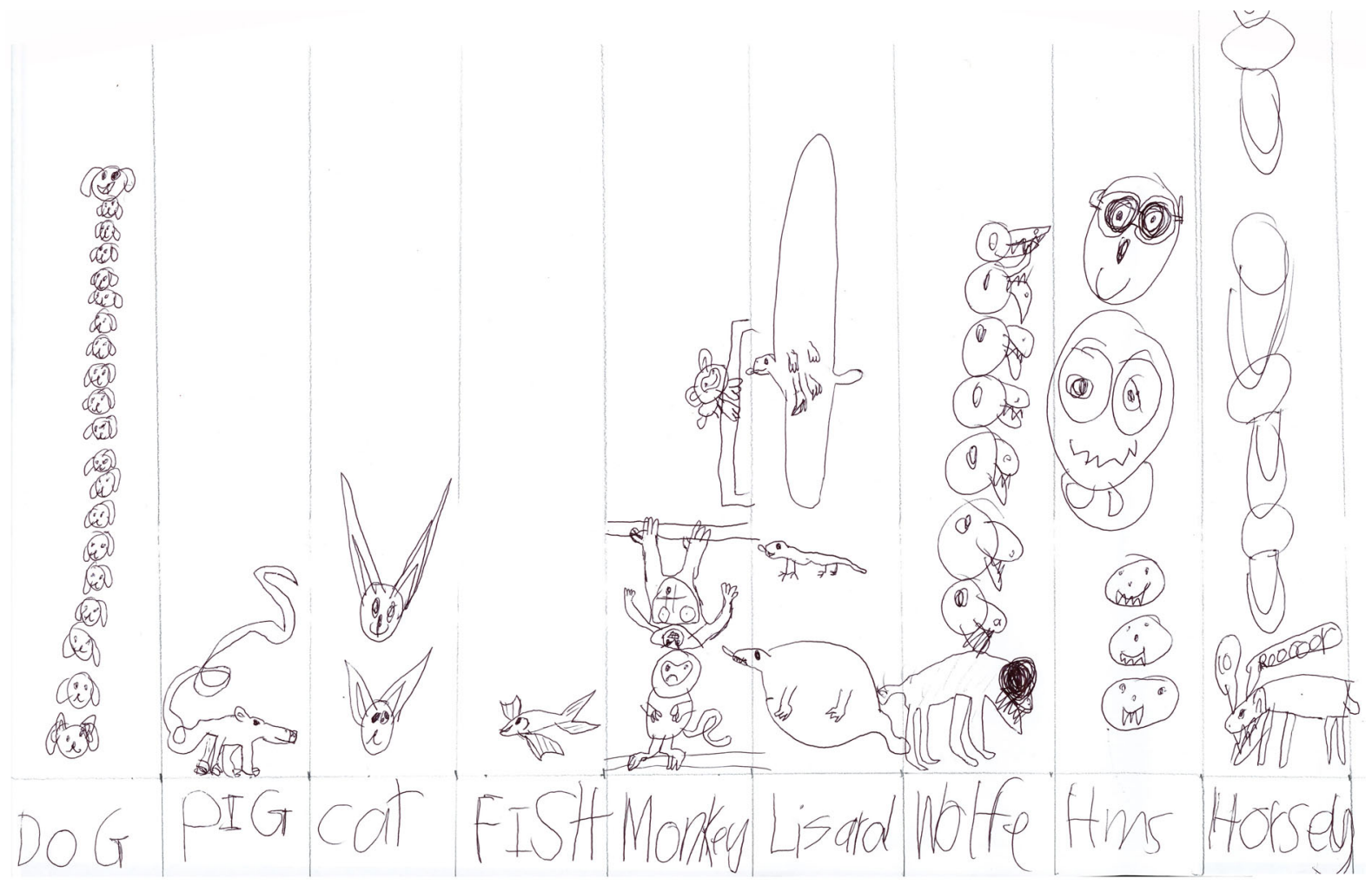

Figure 2 
Figure 3 was drawn by a group of three children working with a non-teacher-researcher who showed them how to use a ruler to make a neat representation of the data. This group already had their own representation of the data in crosses to represent responses against each question. They then used colour coding to link their data list to the graph. The teacher-researcher in question later identified this interaction as an example of a time she should have kept her "hands off the ruler!", showing a conflict between the social and cultural flow of the moment and the polyphonic expectation that the children should be allowed to do the activity on their own.

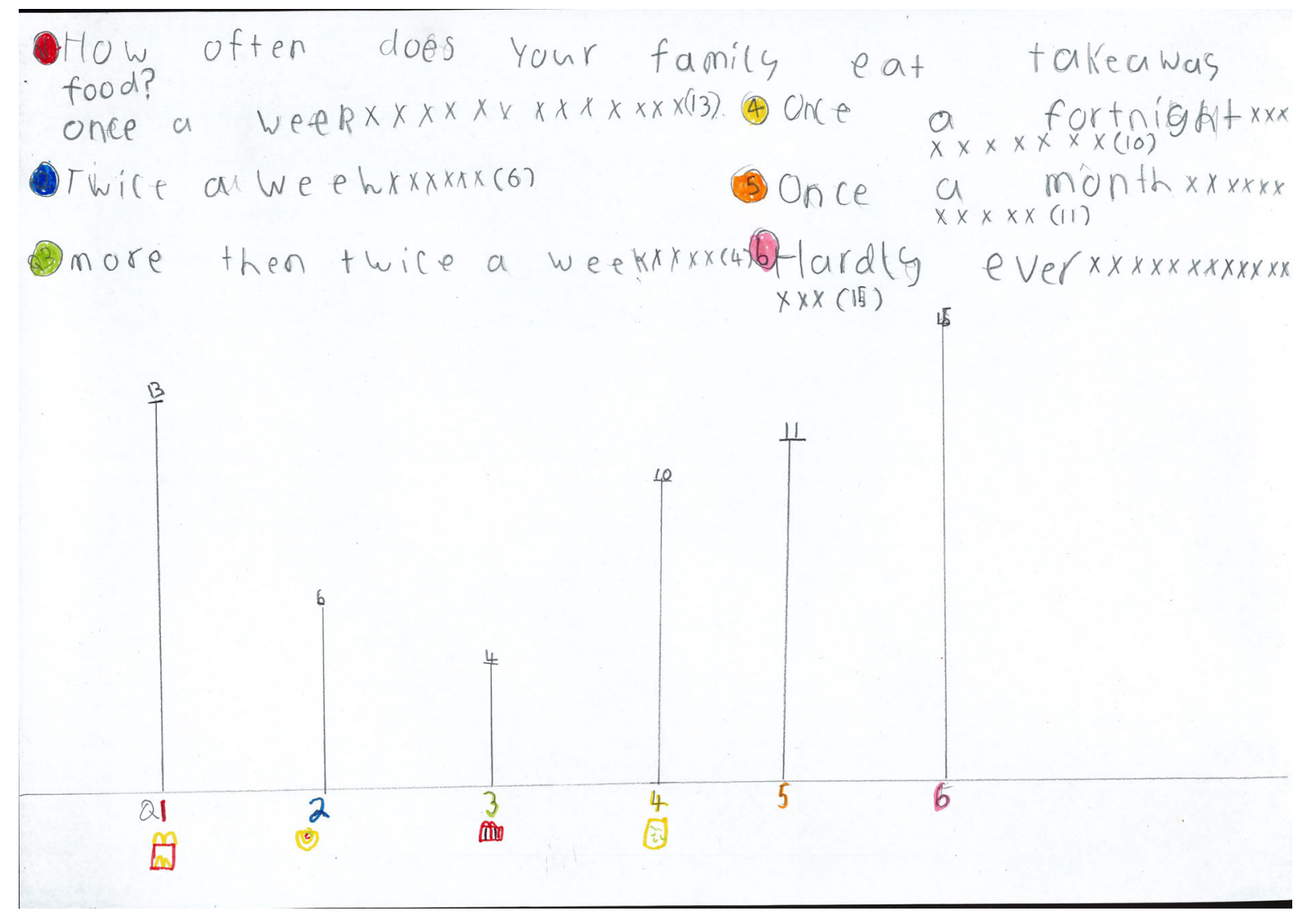

Figure 3

Figure 4 was made by a girl from Grade 3 in response to a teacher researcher asking: "what is the data telling you?". She chose not to graph her data, instead highlighting what the data were saying about the littering habits of grades $1 / 2$ and grades $5 / 6$. Since grades $5 / 6$ were not surveyed, and the results were not what she expected, she concluded that her results may be skewed, reflecting in her notebook that "I think not much people were saying the truth in the survey". This child's approach 
and her hypothesis are congruent with 'being a researcher' and she was rewarded with praise and acknowledgement from all the adult researchers.

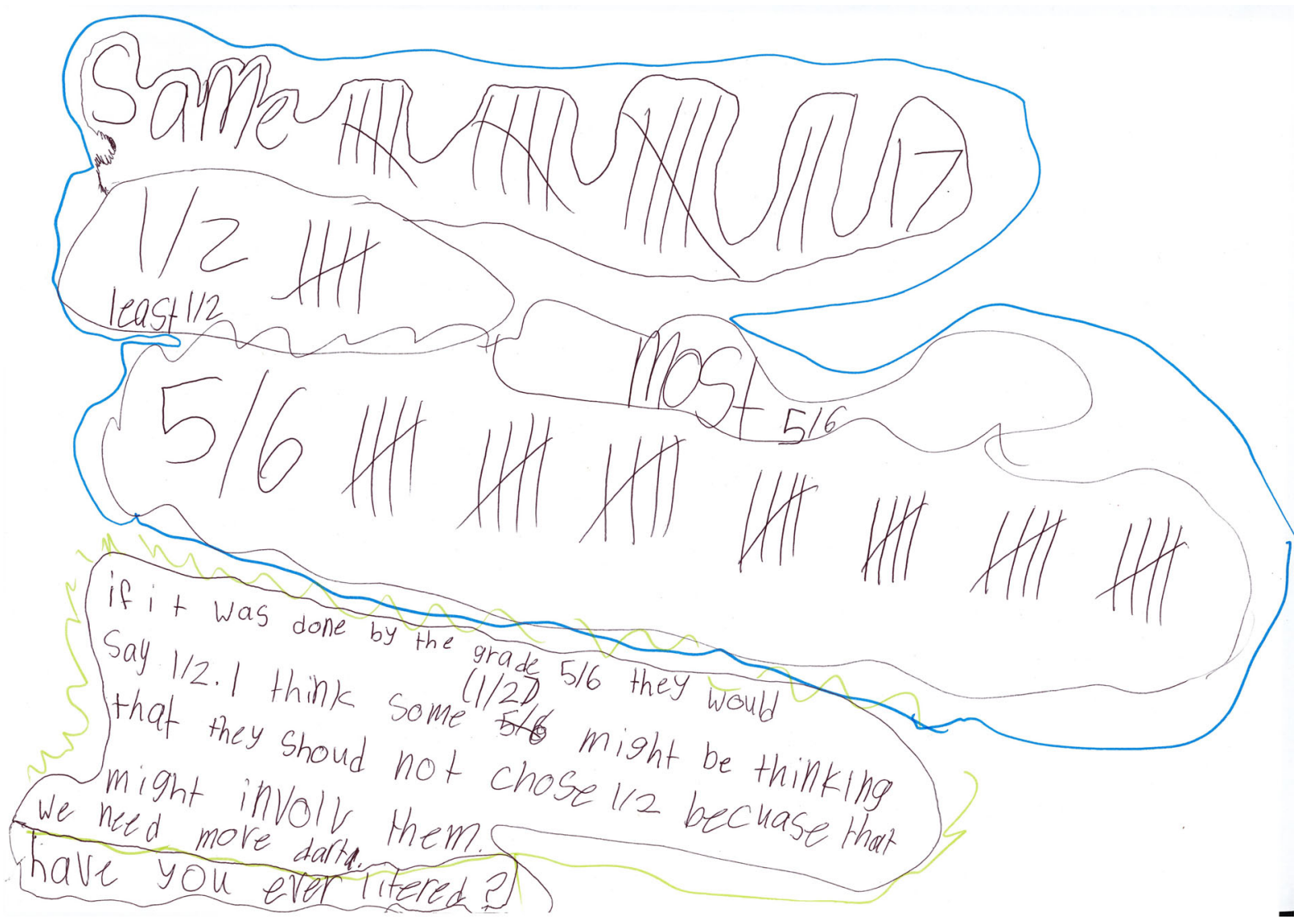

Figure 4

\section{Discussion}

Tassie Researchers was an engaging pedagogical and social experience for the children. It was a rewarding and informative experience for the researchers. Over the course of the project, the children were willing and enthusiastic and did not directly challenge or unsettle adult authority. However, the dialogic imagination reminds us that, if there is no risk to and/or change to the Self, the voices of Others may not have been fully heard (Nealon, 1997; Murray, 2000). Dialogism is not an "empty juxtaposition of opinions, or a flattening-out of perspectives so that all perspectives are equivalent" (Robinson, 2011, p. 10). A dialogical process should be unsettling, as it implies engaging and responding to others as if they really matter (Higham, 2018). That is not to wish for children to be obstructive or difficult. It was clear that the children trusted the format provided by responsible 
'teacher' adults and behaved accordingly. They apparently felt secure and understood expectations. However, the implications of their acquiescence are important. Therefore, the harmonious experience of Tassie Researchers deserves closer examination, acknowledging the chaos of reality (Murray, 2000).

The fact that Tassie Researchers was structured like a classroom activity contributed to children behaving in ways that are acceptable by adults in a school environment (Gallacher and Gallagher, 2008). These behaviours can be described as polyphony, as the children conformed to the dominant narrative of the school situation (Ooi, 2013). The conceptualisation of the project in terms of 'teaching' reinforced a view of children as subordinate and 'incomplete' (Skelton, 2008). We acknowledge that school cultures have developed as a method of facilitating learning and teaching for large groups of students over extended periods of time. We also note that this culture and its associated expectations for specific forms of behaviour and the uptake of responsibility was accepted by all participants. That said, it is important to notice the inevitable influence on children's participation of structures that emphasise their subordinate position as children and as learners. The researchers acknowledge that, had the program been run outside of school and with no teachers present, the heteroglossia would have been different.

In some ways, children were able to shape the situation - such as when they swapped t-shirts and pens or initiated off-topic conversation. As visitors to the school, the researchers could at times speak with the children like peers or collaborators rather than teachers, thus embodying the roles of 'insider and outsider' (White, 2014). Adult control was sometimes unnecessarily dominant - the fact that adults modified some survey questions and prepared the final survey without input from the children is not ideal and, given enough time, the children would likely have been able to arrive at these points themselves. The children made different meanings from this, with one child describing the survey as "our survey" while another described it as "made from our questions". Although the 
impact for each child is impossible to guess, the 'voice' of adult intervention to make the survey 'right' was undoubtedly present.

Carnivalesque tension arose in the context of making data representations. In response to the 'disorder' of children creating their own types of graphs and pictorial representations, one researcher took a ruler and demonstrated a way of depicting the data that accorded with the polyphony of doing research. Had this researcher refrained from ordering the children's work, their understanding of and relationship with the data would have been different. This is not to say that the result would have been a 'truer' or better depiction of the data. It should also be acknowledged that some children asked about how to represent their data 'properly'. However, had the researcher resisted the impulse to take up the ruler, the children's process of connecting their experience and their choices with the task would have been acknowledged and given space to unfold.

The differences of position between the adult researchers and between the researchers and children represents its own heteroglossia. The teacher-researchers alone used the clapping rhythm to attract attention, and the children made overtures of friendship primarily to the non-teacher-researchers such as sitting very close and/or revealing secrets and details about their lives. The 'outsider' status of the researchers was highlighted by the gifting of t-shirts, reflection notebooks and stationery sets containing 'luxury' items such as scented textas, sticky-notes and highlighter pens. The lunch was also 'special' because it was provided free and only to these children in the school. These elements would be unexpected in a school environment. The extent to which the children perceived such gifts as requiring reciprocity - for example by fulfilling the perceived expectations of the researchers - is unknown but must also be acknowledged. At the very least, these elements were genre-defining and carried unspoken expectations, as well as constituting rewards that raised the value of the children's participation.

The research produced by the children was significant. It reflected things of importance in their worlds, such as littering, time spent gaming, diversity of languages, bedtimes, and levels of fast-food 
consumption. However, the nature of the project meant that less emphasis was placed on the implications of their findings than on their learning and their identities as 'researchers'. The Governor of Tasmania found time to visit the school, and although she viewed the data representations, her focus was on speaking with the children about their experience of being Tassie Researchers and answering their questions about her life, rather than on their work. Dissemination of the children's findings was facilitated through significant platforms of the children's choice school assembly, the Governor of Tasmania, local radio; however, overall, the focus became less on their findings than on their precocious learning.

The question of impact has sparked discussions between the authors, driven by the knowledge that the findings of children's participation in research are often not adequately acted upon (Lundy, 2007). Although we are of the view that researchers do not necessarily carry responsibility for effecting impact with their work, we are cognisant of the fact that these children embodied multiple roles, including children, learners, and researchers, and that their status as learners led to reduced emphasis on impact. The project could certainly be said to have developed the voices of children, giving them a clearer understanding of their own views and their world, as well as the skills to investigate further. They also gained awareness of their ability to create new knowledge as opposed to collecting existing knowledge. However, in hindsight, there is scope for inclusion of a session with the children focused on the implications of their findings, and what the next step might be.

The children in the Tassie Researchers project investigated significant questions and used data to create new knowledge on their topics; negotiated the social and behavioural conventions of being a researcher; engaged with the sensory and genre-shaping experience of t-shirts, stationery and food; developed their existing relationships with each-other and began new ones with the visiting adults; learned new skills and practised different ways of thinking; and recognised that their experiences were interesting to a broad audience. Examining Tassie Researchers through the heuristic of heteroglossia, polyphony and the carnivalesque facilitates recognition of all aspects of the project, 
but particularly those that may seem incidental to adults while being important to children. The dialogic imagination supports adult openness to the otherness of children, without sacrificing responsibility to adult goals and motivations (Murray, 2000). Identifying all the voices in a communicative space clarifies who is speaking as well as what is being said (Gonzalez, HernandezSaca and Artiles, 2017). Accepting that children can contribute to the heteroglossia through polyphony and the carnivalesque gives them the opportunity to participate in ways not defined by adults, which constitutes a more ethically sound engagement (Gallacher and Gallagher, 2008).

There are practical implications for our analysis. We suggest that the ontological understanding facilitated by the dialogic imagination encourages self-critical reflection among adults, supporting conceptions of children and childhood that go beyond age or development (Alanen, 2009; Spyrou, 2019). Recognising heteroglossia and polyphony encourages communication with children, including responses to carnivalesque moments, as if they really matter (Higham, 2018). Identification of all the 'voices' present in a situation supports understanding of what is important to all participants and reveals tension between different perspectives and motivations. In teaching situations, in which the need for learning objectives may seem incompatible with the dialogic imagination, we argue that awareness of multiple layers and shifting meanings informs moment-to-moment teaching decisions in positive ways, including valuing the social and role-related processes of connecting knowledge and building understanding. Further, openness to and acceptance of situational tension and seeming disorder, even in small ways, accommodates social learning and the potential for creativity and unexpected outcomes (Wegerif, 2008). This is a stance that supports children in accessing new genres of being, reveals voices that are dominant, acquiescing, invoking, silent or omitted, and highlights things that are obscured.

\section{Conclusion}

Imagining situated interactions between adults and children in terms of heteroglossia, polyphony and the carnivalesque provides an ontological framework for conceptualising the roles and 
experiences of each participant. The conceptualisation of childhood that is adopted in childhood studies has clear material consequences for the children concerned, as pointed out by Spyrou (2019, p.321). The authors have reflected on what was brought forth through the Tassie Researcher methodology. Our primary intention to regard children as agents was in tension with a method that positioned the children as needing to learn and refine an agentic skill (that is, research methods and knowledge dissemination strategies). The authors' epistemological positioning was shifting and paradoxical. Importantly, tensions within the situation are acknowledged and appreciated as potential sources of inspiration, learning and change. The dialogic imagination requires openness to the voices of participants and the situational context, and willingness to allow transgressions and fluctuations of agentic power relations. This is an ontology that allows for the shifting roles and identities occupied by both adults and children. Allowing these to manifest gives children the chance to engage with their social and learning experiences. It also allows for positioning by children in important and, at times, unexpected ways, and promotes the 'risk' of children unsettling, challenging and/or changing adults and their expected outcomes. 


\section{REFERENCES}

Alanen, L. (2009) 'Generational order', in The Palgrave handbook of childhood studies. Palgrave Macmillan, pp. 159-174.

Baker, B. (1999) 'What is voice? Issues of identity and representation in the framing of reviews', Review of educational research. Sage Publications, 69(4), pp. 365-383.

Bakhtin, M. (1984) Problems of Dostoevsky's poetics. Edited by C. Emerson. Minneapolis: University of Minnesota Press.

Crowley, A. (2015) 'Is anyone listening? The impact of children's participation on public policy', The International Journal of Children's Rights, 23(3), pp. 602-621.

Gallacher, L.-A. and Gallagher, M. (2008) 'Methodological immaturity in childhood research? Thinking through "participatory methods"', Childhood, 15(4), pp. 499-516.

Gonzalez, T. E., Hernandez-Saca, D. I. and Artiles, A. J. (2017) 'In search of voice: theory and methods in K-12 student voice research in the US, 1990-2010', Educational Review, pp. 451-473. doi: 10.1080/00131911.2016.1231661.

Grace, D. J. and Tobin, J. (2002) 'Pleasure, creativity, and the carnivalesque in children's video production', in Bresler, L. and Thompson, C. (eds) The arts in children's lives. Dordrecht: Kluwer Academic Publishers, pp. 195-214.

Harden, J., Scott, S., Backett-Milburn, K., Jackson, S. (2000) 'Can't talk, won't talk?: methodological issues in researching children', Sociological Research Online, 5(2), pp. 1-12.

Higham, R. (2018) '“To Be Is To Respond": Realising a Dialogic Ontology For Deweyan Pragmatism', Journal of Philosophy of Education, 52(2), pp. 345-358. doi: 10.1111/1467-9752.12290.

Honig, M. S. (2009) 'How is the child constituted in childhood studies?', in Qvortrup, J., Corsaro, W., and Honig, M. (eds) The Palgrave Handbook of Childhood Studies. Palgrave Macmillan UK, pp. 62-77. Horgan, D. (2017) 'Child participatory research methods: Attempts to go "deeper"', Childhood, 24(2). doi: $10.1177 / 0907568216647787$.

Keegan, N. L. (2019) 'Children who say hand dryers "hurt my ears" are correct: A real-world study examining the loudness of automated hand dryers in public places', Paediatrics \& Child Health. 
Kellett, M. (2010) 'Small shoes, big steps! Empowering children as active researchers', American journal of community psychology. Wiley Online Library, 46(1-2), pp. 195-203.

Lundy, L. (2007) “Voice'is not enough: conceptualising Article 12 of the United Nations Convention on the Rights of the Child', British Educational Research Journal, 33(6), pp. 927-942.

Lundy, L. and McEvoy, L. (2012) ‘Children's rights and research processes: Assisting children to (in) formed views', Childhood, 19(1), pp. 129-144.

Mallan, K. (1999) 'Children's storytelling as carnivalesque play', International Journal of Phytoremediation, 20(1), pp. 113-123. doi: 10.1080/0159630990200107.

Mckenzie, J. (2005) 'Bums, poos and wees: Carnivalesque spaces in the picture books of early childhood. Or, has literature gone to the dogs?', English Teaching: Practice and Critique, 4(1), pp. 8194.

Morrow, V. (2005) 'Ethical issues in collaborative research with children', in Farrell, A. (ed.) Ethical research with children. Berkshire, UK: McGraw-Hill Education, pp. 150-165.

Murray, J. W. (2000) 'Bakhtinian answerability and levinasian responsibility: Forging a fuller dialogical communicative ethics', Southern Communication Journal, 65(2-3), pp. 133-150. doi: 10.1080/10417940009373163.

Nealon, J. (1997) 'The ethics of dialogue: Bakhtin and Levinas', College English, 59(2), pp. 129-148. O'Donnell, H. (2017) 'UFA Young Researchers and Evaluators Impact Report', Journal of extension, 34(6). Available at: http://www.childrensuniversity.co.uk/media/2074975/ufa-report-final.pdf.

Ooi, C. (2013) How to Capture and Present Complexity, Ambivalence and Ambiguity: Applying Dialogism in Social Science Research. CLCS Working Paper Series Copenhagen Business School. Robinson, A. (2011) 'In Theory Bakhtin: Dialogism, Polyphony and Heteroglossia', Ceasefire Magazine. Available at: https://ceasefiremagazine.co.uk/in-theory-bakhtin-1/.

Save the Children (2010) Child Carers: Child-led research with children who are carers.

Skelton, T. (2008) 'Research with children and young people: exploring the tensions between ethics, competence and participation', Children's Geographies, 6(1), pp. 21-36.

Spyrou, S. (2016) 'Researching children's silences: Exploring the fullness of voice in childhood research', Childhood, 23(1). doi: 10.1177/0907568215571618.

Spyrou, S. (2019) 'An Ontological Turn for Childhood Studies?', Children and Society. Blackwell 
Publishing Ltd, 33(4), pp. 316-323. doi: 10.1111/chso.12292.

Thomas, N. (2017) 'Turning the tables: children as researchers', in Christensen, P. and James, A. (eds) Research with children: Perspectives and practices. London: Routledge, pp. 160-179.

Wegerif, R. (2008) 'Dialogic or dialectic? The significance of ontological assumptions in research on educational dialogue', British Educational Research Journal, 34(3), pp. 347-361.

Wegerif, R. (2019) 'Towards a dialogic theory of education for the Internet Age.', in The Routledge International Handbook of Research on Dialogic Education. Routledge, pp. 14-26.

White, E. J. (2014) "Are You “Avin a Laff?": A pedagogical response to Bakhtinian carnivalesque in early childhood education', Educational Philosophy and Theory. Routledge, 46(8), pp. 898-913. doi: 10.1080/00131857.2013.781497.

Wright, S., Fitzallen, N., Shelley, B., Lang, M. (2019) 'Inspiring the next generation of scientists: Children as researchers and storytellers', Teaching Science, 65(4), pp. 11-25. 